\title{
Children's Relative Appellations Acquisition in the Framework of Prototype Theory
}

\author{
Liusheng Shi \\ Department of Foreign Languages and Literatures, School of Humanities, Tsinghua University, \\ Beijing 100084, China \\ sls15@mails.tsinghua.edu.cn
}

\begin{abstract}
Relative appellations are the earliest acquired nouns of children, and their acquisition principles are analyzed and understood by prototype theory in this paper, and judgment experiments are designed to test the concrete prototype of kindergarten children on relative acquisition. This essay will firstly lay out how the experiments are being conducted. Then it will discuss the reason and conclusion behind the experiment results. Finally, the results show that children have the ability of morphemes combination in acquiring relative appellation. It is concluded that children should have a hidden learning module hidden in the framework of UG when acquiring languages at an early stage, which helps children cut and combine morphemes in relative appellations, at the same time, and a dynamic boundary of prototype appears in the research which support the revision of the prototype theory.
\end{abstract}

Keywords: Relative appellations, children acquisition, prototype theory.

\section{Literature Review}

Prototype theory is put forward by combining the common research achievements of philosophers, anthropologists, psychologists and linguists. The philosopher Wittgenstein (1953) [1] put forward the concept of family similarity in his book philosophical investigation. He pointed out that some categories are defined by family similarity (such as game category). Members have some characteristics similar to those of other members, but it is difficult to find out what characteristics are shared by all members. While anthropologist Berlin \& Kay (1969) [2] inspected color words in 98 languages, and found that categorization of colors actually followed certain rules, and found the focus color phenomenon in their research. Psychologist Rosch (1975) [3] made several famous experiments on the phenomenon of focus color, and found that focus color played a role of cognitive reference point in people's color categorization. Rosch calls this cognitive reference point prototype. Subsequently, Rosch extended the prototype experiment to other kinds of experiments, such as birds, fruits and the like. The experimental results also confirmed the existence of prototype. The experiments of linguists Lakoff (1987) [4] and Taylor (1989) [5] proved that boundary ambiguity exists in the process of human categorization. Prototype Theory provides a new perspective to delimitation of attributes. It outgrows the traditional establishes significant relationship and binary thinking between subjective experience and objective recognition, which promotes people to reconsider varieties of notions in many subjects. Since the 1980s, scholars abroad have introduced many prototype theories into translation studies (Halverson, 1997; 1998; 2000; 2002, Neubert, 1985; Snell-Hornby, 2001; Neubert \&Shreve, 1992 ;). They regard translation as a prototype category based on theoretical deduction and/or empirical studies.

Combining with this series of research findings, Rosch put forward the famous prototype theory. This theory holds that the members of a category do not need to meet a series of necessary and sufficient conditions, and the members of the category are divided into subordinate degrees. The central member or the best member is called the prototype, the marginal members are linked according to the similarity with typical members, and the boundaries of the domain are fuzzy. Armstrong et al [6] puts forward that the category still needs the existence of real essence after discovering that prototype theory can't explain the problems of odd number and even number. Osherson and Smith also agree with Rosch's experimental findings, and at the same time propose that the category still needs to be composed of "core definition" and "identification procedure". Armstrong et al puts forward that prototype theory lacks essential attributes and a clear boundary. As 
for essential attributes, one kind of things can be distinguished from other kinds of things by its essential characteristics rather than others. A word is a symbol of an objective object. If the reflection of word meaning does not contain enough features to distinguish the class object from other objects - essential features, then the word cannot play a role as a symbol. Therefore, the reflection of word meaning must include the essential features of the objective object, even if it is only an essential feature. For example, ' having high-level nerve activity', ' having limbs', ' being able to nurse', ' being able to talk', ' being able to make tools' and so on, they are all common characteristics of human beings, but only the latter two are essential characteristics of human beings. And a revised version of prototype theory be purported in Smith \& Samuel (1997) [7] puts forward that the category is not fixed, but dynamic, and it will be constructed online as soon as it is needed. That is to say, the boundary of category has been reinterpreted online.

In recent years, after realizing the theoretical values of prototype theory, scholars in China like Li Heeling and Zhang Shining (2003), Wang Renqiang and Zhang Yihua (2004), Yang xiaohong (2008), Jin Shengxi and Wang Dan (2006) and, Huang Qiongying (2007) and Mao Zhongming and Zhou Fugan (2007) have also attempted to integrate prototype theory into translation studies. Yang(2008) [8] purported that all attributes of a category are divided into essential attributes and non-essential attributes, and members of a category need not possess all attributes, but must at least possess essential attributes. The more non-essential features, the higher the typicality of the members. What owns all the attributes is the prototype of the category, and the core of the category is composed of the collection of essential attributes, that is, the stable part. The boundaries of categories are clear and move with the increase or decrease of non-essential attributes. It can be said that this kind of category structure is just like the ripples on the lake. The intensity of ripples weakens with the spread of ripples, and the edge part of ripples may intersect with the edge part of another ripple, thus forming fuzzy boundaries.

\section{Materials and Design}

The relative appellations in children's language are the first words which are acquired by them, such as father and mother, besides, it is the starting point of natural language system acquisition for children. Therefore, the research in acquisition of relative appellations in children's language is of great significance which is in favor of exploring the process and mechanism in the acquisition of words meaning for children. This paper can provide corresponding experimental data support for the correction of prototype theory, and inject new vitality into the continuous correction of prototype theory. And can have a more in-depth understanding of children's language acquisition and a deep characterization of their acquisition strategies.

This essay selected two children out of Brown corpus in CHILDS database to understand the frequency of each relative appellations. There are three key elements to CHILDS database which can be categorized as the database, CHAT transcription system and the CLAN programs. CLAN format is used in every Brown corpus which is named after the experimented. Three large longitudinal corpuses are selected in Brown's corpus, but only two of them will be used in this essay, among which are Adam and Sarah. Adam is used to refer as male and will be experimented with 30 sessions of one hour. Meanwhile, Sarah is used to describe female to go under an experiment of 60 sessions with one session around an hour. They are required to do whatever they like as what they are doing every day, like book reading or toy playing. The result combines literature materials and mathematical statistics. SPSS 17.0 will also be used to further understand the figures.

Table 1. Two Children's Types and Tokens on Proper Names

\begin{tabular}{|c|c|c|c|c|}
\hline \multirow{2}{*}{ Classification/Subject } & \multicolumn{2}{|c|}{ ADA } & \multicolumn{2}{c|}{ SAR } \\
\cline { 2 - 5 } & Types & Tokens & Types & Tokens \\
\hline Kinship terms & 11 & 875 & 18 & 593 \\
\hline Names of organs & 47 & 341 & 41 & 369 \\
\hline Names of clothes & 22 & 124 & 28 & 129 \\
\hline
\end{tabular}


As for ADA, the word "mommy" is the prototype which is being most spoken among all the tokens, followed by "malma", "grandfather", "mother", "brother", "momma", "grandmother", "sister", "father" and so on. The most spoken word for SAR is the same which is "mommy", followed by "daddy", "mummy", "momma", "mom" and so on (Wescott, 2010) [9].

Relative appellations are among the first acquisitions that children learn from their early age and also the start of learning of every new word. The understanding and usage of children's relative appellations can be related to children's cognition of age, gender and relative relationship (Ritchie, 1996) [10]. Therefore, children's relative appellations acquisition is crucial to the process and mechanism of children's acquisition of meanings. The corpus being used in the following research is surveys of different age groups. Children ahead of age 5 will be used as examples in this essay. 5 years of age will be divided into 9 groups with half an age as a group and 15 random selected groups will be used in the survey. Experimental method is also being used for a more accurate result ( $\mathrm{Au}$, 1994) [11].

Children's relative appellations acquisition is closely related to family background and environment. The 1:0 5:0 children's corpus involved 24 relative appellations. They are earlyappeared in time with 2191 times, among which "mama" is the most called, which is 699 times, taking up $31.9 \%$ of the total. The calling of "papa" takes up 636 times with $29 \%$ of the total. "Uncle" appeared for 227 times for $10.3 \%$ of the total and "grandpa" for 75 times for $3.4 \%$. The word "grandma" is murmured for 145 times which is $6.6 \%$ of the total calls and "aunt" for 55 times, taking up 2.5\%. "Brother" for 48 times and "sister" for 59 times, accounting for $2.1 \%$ and $2.6 \%$ respectively. The frequency of other relative appellations in the survey is below $1 \%$. The first time these words being heard are listed below (William, 2005) [12].

Table 2. The First Time of Relative appellations' Appearance

\begin{tabular}{|c|c|c|c|c|c|c|}
\hline \multirow{2}{*}{ Age } & \multirow{2}{*}{ 11 months old } & $1: 0$ & $1: 1$ & $1: 2$ & $1: 6$ & $2: 0$ \\
\hline \multirow{3}{*}{ relative appellations } & \multirow{3}{*}{ Mama } & \multirow{2}{*}{ Papa } & Aunt & Uncle & Sister & Younger sister \\
\cline { 4 - 6 } & & & Grandma & Daddy & Brother & Younger brother \\
\cline { 3 - 6 } & & & Grandpa & Mr & & \\
\cline { 3 - 4 } & & & Mrs & & \\
\hline
\end{tabular}

A real situation experiment is done to experiment groups in this essay. When the child is being asked "where is your daddy?" he turns his head to his father, even when he is being held by his mother. What is more, when being asked about his mother, he does the right head turning again. It can be concluded that understanding goes before expression. Children are able to identify his father or mother long before the respective relative appellations are learnt. The cognitive competence is the psychological foundation of children's acquisition of relative appellations.

In the early times, children cannot live on their own and rely on grown-ups to help with daily chores like eating, walking and grabbing. These interactions make them to understand that precise expression of feelings and wishes are essential to meet their material or mental needs. Despite the internal needs for relative appellations, repeated language input from adults also has a significant impact on children's acquisition of relative appellations (Bloom, 2000) [13].

The survey also showed that before 1:1 relative appellation like "mama", "papa", "grandpa", "grandma" already appeared. The corpus also recorded a miscalling of "grandpa" to "papa", which is resulted in regional dialects (Huang, 2013) [14].

\section{Results}

The prototype theory also supports the idea how children develop their relative appellations. The prototype of relative appellations is first built by an individual sample like their own grandfather, which contains a lot of characteristics. Sensory perception helps the child to memorize a certain set 
of rules along with relative appellations (Nelson, 1975) [15]. For example, for the relative appellations of "grandpa", children tend to start from their own grandfathers and figure out that "white hair", "long beard", "wrinkled face", "stiff body" are some of the main characters enjoyed by this word. Another example is the word "uncle" carries the same character as a man who is little older or younger than his own father (Halliday, 1975) [16].

In the experiment, the first word being said by children is "mama", which is understood in the wrong way in many children's minds. Children are experimented to call their father "mama" when they are 305 days old. They confuse the word "mama" with their grandmother at 293 days old (Gentner, 1982) [17]. When the experiment gets to 1:0, the word "papa" appeared, and it is being mixed along with any other male the children may see. The words like "grandpa", "grandma" and "aunt" experience an extension of meaning at the stage at 1:1. They may refer to any person who is around the same age or their real relatives (Zhu, 2001) [18].

The answer to when children acquires and how often they use these words lie in the early growingup environment and the intimated family members. The word "mama" and "papa" are the first appeared ones. Sensory perception is an important way for baby to understand the world and itself at an early stage. Children rely on sensory perception to lead them feel the motion and understand everything around them. The sensory perception grows as children interact with the outer world so that the children will eventually tell the difference. Experiment says that a 3-month-old baby is able to sort out his mother among all range of pictures. A 5 to 7-month-old baby can tell apart between other stimuli (Vihman, 1995) [19].

The priority of how the children learn their relative appellations according to a certain procedure. It is clear from the experiments that the acquisition of relative appellations are mostly related with family background and living conditions. Therefore, the exact time of when they learn their first relative appellation is different. However, for each child, it can be concluded that members within their immediate families are the first names to be remembered, then comes with the non-immediate family members. The intensity of the member's presence in the children's life can be resulted in the first learned words. Parents are usually the center of children's early life. Cries can be used as a powerful tool to contact their parents and become the first tool they use. However, cries have limited meanings and a change in tone and accent may be used for conveying various meanings. During this process, the children find out that "papa" and "mama" are perfect for getting across. And parents are also the ones who will put a lot of repeated effort into teaching the children of how to pronounce the words correctly.

"Papa" and "mama" are the first words to learn also is resulted in Principle of maximum contrast, which is the easiest syllables for children to pronounce is the one with the most contradiction between consonant and vowels (Jakobson, 2011) [20]. The word "mama" and "papa" can be seen as perfect examples. It also explains why the pronunciations for "papa" and "mama" in different cultures tend to be very similar. The repeated syllables can help the children to reduce the difficulty in pronunciations, and making it easier to understand.

Other words can be learnt in the later part of the sensorimotor period, as it is shown from the chart after 1:6. The relative appellations in this period can be hard to figure out with the complicated family relationships, but can be learnt from teaching, which is specialized acquisition of relative appellations. If the child is close to one of these relatives in his early age, as it is the case for one of the experiment subjects, it is highly possible that the child will learn the relative appellations ahead of other words.

\section{Conclusion}

In conclusion, the children acquisition of relative appellations is following a certain pattern from the perspective of Prototype theory. The priority in the acquisition is mainly related to the frequency of interactions between the child and the relative. What is more, the relationship can also be found in the literal meaning and function of relative appellations. Another factor is the teaching method from adults and the difficulty of pronunciation of the relative appellation's words. And this kind of combination responds to the logical problem in language acquisition why children can develop an 
excellent language production in such a short time, thus we wonder whether there is a learning module is hidden in the frame of UG, which helps children gradually open some parameters operations to acquire the ability of combination.

\section{References}

[1]. Wittgenstein, L. (1953). Philosophical investigations. Philosophische untersuchungen. Philosophische Untersuchungen=Philosophical investigations.

[2]. Berlin, B., \& Kay, P. (1969). Basic color terms: their universality and evolution. University of California Press.

[3]. Rosch, E. (1975). The nature of mental codes for color categories. Journal of Experimental Psychology Human Perception \& Performance, 1(4), 303-322.

[4]. Lakoff, G. (1987). Cognitive models and prototype theory. In U. Neisser (Ed.), Emory symposia in cognition, 1. Concepts and conceptual development: Ecological and intellectual factors in categorization (pp. 63-100). New York: Cambridge University Press.

[5]. Taylor, \& Charles. (1989). Sources of the self: the making of the modern identity. Harvard University Press.

[6]. Taylor, J. R. (2001). Linguistic Categorization: prototypes in linguistic theory. Foreign Language Teaching and Research Press: Oxford University Press.

[7]. Smith, L. B., \& Samuelson, L. K. (1997). Perceiving and remembering: category stability, variability, and development.

[8]. Xiaohong Yang. (2008). Research on prototype theory of cognitive linguistics. Modern Chinese. Language study Edition (3), 8-10.

[9]. Wescott, R. W. (2010). Linguistics: psycholinguistics.dan i. slobin. American Anthropologist, 76 (1), 159-160.

[10]. Ritchie, William, C. (1996). Handbook of child language acquisition. Academic press.

[11]. Au TKF, Dapretto, M. Song, Y.K. (1994). Input versus constraints: Early word acquisition in Korean. Journal of Memory and Language.

[12]. William O’ Grady. (2005). How children learn language. Cambridge University Press.

[13]. Bloom, P. (2000). How children learn the meanings of words. Cambridge, Massachusetts: MIT Press.

[14]. Huang, Z. Y. (2013). On relative appellations in Chinese dialect spoken in Guangxi beibu gulf coast__ a case study of Qinzhou dialect. Journal of Guangxi University for Nationalities.

[15]. Nelson, K., Hampson, J., Shaw, L.K. (1993). Nouns in early lexicons: evidence, explanations and implications. Journal of child language.

[16]. Halliday, M. A. K. (1975). Learning how to mean. Foundations of Language Development.

[17]. Gentner, D. (1982). Why nouns are learned before verbs: linguistic relativity versus natural partitioning. Hillsdale, NJ: Erlbaum.

[18]. Zhu, W. X. (2001). Relative appellations in children's language. Journal of Anhui Normal University.

[19]. Vihman, M. M. (1995). Phonological development - the origins of language in the child. DACS. 
[20]. Jakobson, R., \& Macmahon, M. K. C. (2011). Child language, aphasia and phonological universals. International Journal of Language \& Communication Disorders, 4(2), 208-209. 